\title{
Experimental study of degradation and biodegradability of oxytetracycline antibiotic in aqueous solution using Fenton process
}

\author{
Mustapha Zouanti ${ }^{1^{\dagger}}$, Mohamed Bezzina ${ }^{1}$, Ramdhane Dhib ${ }^{2}$ \\ ${ }^{1}$ VSN Laboratory, Faculty of Science and Technology, University of Djilali Bounaama, Khemis Miliana, 44225, Algeria \\ ${ }^{2}$ Department of Chemical Engineering, Ryerson University, 350 Victoria Street, Toronto, Ontario, Canada
}

\begin{abstract}
The degradation of aqueous oxytetracycline (OTC) from an aqueous solution antibiotic using $\mathrm{H}_{2} \mathrm{O}_{2} / \mathrm{Fe}^{2+}$ process was studied in one $1 \mathrm{~L}$ batch chemical reactor. The extent of OTC degradation $(20 \mathrm{mg} / \mathrm{L})$ was investigated from a known initial $\mathrm{pH}$ solution, temperature and the type of catalyst $\left(\mathrm{Fe}^{2+}, \mathrm{Fe}^{3+}\right)$ and for various initial concentrations of $\mathrm{OTC}, \mathrm{H}_{2} \mathrm{O}_{2}$ and $\mathrm{Fe}^{2+}$. The degradation efficiency achieved was found to be very important $(90.82 \%$ and $90.63 \%)$ at initial $\mathrm{pH}$ solution of 3 and 4 , respectively. However, the type of catalyst and the reaction temperature had a slight impact on the final degradation of OTC. The results showed that the OTC removal increased with increasing initial $\mathrm{H}_{2} \mathrm{O}_{2}$ concentration in the range of 70 to $150 \mathrm{mg} / \mathrm{L}$ and initial $\mathrm{Fe}^{2+}$ concentrations in the range of 2 to $5 \mathrm{mg} / \mathrm{L}$. The highest degradation efficiency obtained at ambient temperature was 90.95\% with initial concentration of OTC of $10 \mathrm{mg} / \mathrm{L}, \mathrm{H}_{2} \mathrm{O}_{2}=150 \mathrm{mg} / \mathrm{L}$ and $\mathrm{Fe}^{2+}=5 \mathrm{mg} / \mathrm{L}$. Moreover, biodegradability improved from 0.04 to 0.36 and chemical oxygen demand degradation was $78.35 \%$ after $60 \mathrm{~min}$ of treatment. This study proved that Fenton process can be used for pretreatment of wastewater contaminated by OTC before a biological treatment.
\end{abstract}

Keywords: Advanced oxidation processes, Chemical degradation, Fenton process, Oxytetracycline, Pharmaceutical wastewater

\section{Introduction}

Effluents of waste products coming from pharmaceutical industry enter environmental ecosystems through various channels such as pharmaceutical equipments, wastewater treatment plants and medical center wastes [1,2]. During the last few decades, the production and consumption of pharmaceutical products have drastically increased due to the considerable usage of medical products by the fast growing world population. Today, large quantities of medical products are produced each year for human and animal healthcare [3]. As a result, huge quantities of wastewaters are proportionally generated in pharmaceutical industries and medical centers. These relevant wastes are characterized by a high biochemical oxygen demand (BOD), chemical oxygen demand (COD), total suspended solids and toxicity. Besides, the effluents contain important amounts of toxic and persistent compounds such as organic solvents, catalyst, reactants and raw materials [4-7].
Antibiotics are among the most widely used drugs for the treatment of diseases. In particular tetracyclines (TCs) stand out as one of the most important antibiotic groups in terms of high production and worldwide distribution [8]. TCs are broad-spectrum of bacteriostatic antibiotics that are effective in treating infections caused by certain strains of Gram-negative and Gram-positive, which explains their wide use in the treatment of infectious diseases for humans and animals [9]. In fact, the most extensively used TCs are oxytetracycline (OTC), TC, chlortetracycline (CTC), and doxycycline (DC). TC is frequently used in aquaculture and veterinary [10], whereas OTC and CTC are widely administrated as growth promoters. Therefore, it is possible to find these antibiotics discharged into the environment. For instance, the concentration of TCs detected in surface water is in the range of 0.11 to 4.20 $\mu \mathrm{g} / \mathrm{L}$ and in wastewater treatment plant (WWTP) effluents with concentrations of 46-1,300 ng/L for TC, 270-970 ng/L for CTC, and $240 \mathrm{ng} / \mathrm{L}$ for OTC [11]. Kolar et al. [12] found that OTC was

Received September 28, 2018 Accepted May 8, 2019

${ }^{\dagger}$ Corresponding author

Email: m.zouanti@univ-dbkm.dz

Tel: $+213-27556844$

ORCID: 0000-0002-5215-5595 Copyright (c) 2020 Korean Society of Environmental Engineers

This is an Open Access article distributed under the terms of the Creative Commons Attribution Non-Commercial License (http://creativecommons.org/licenses/by-nc/3.0/) which permits unrestricted non-commercial use, distribution, and reproduction in any 
moderately toxic to organisms of activated sludge $\left(\mathrm{EC}_{50} 17.9 \mathrm{mg} / \mathrm{L}\right)$. Therefore, it is necessary to develop appropriate techniques for the removal of these pollutants from contaminated wastewaters for preserving the environment.

Biological processes are quite economical for the treatment of wastewaters and they are widely studied. But, they have been proven to be ineffective in the removal of persistent or non-biodegradable compounds [13]. For instance, biological treatment processes are not successful in effectivelly removing TCs antibiotics [14]. Alternatively, physico-chemical techniques such as reverse osmosis, adsorption, ultrafiltration and coagulation are also used for the treatment of wastewater, however these treatments transfer only the pollution from one phase to another, which subsequently requires further treatment $[13,15]$. Therefore, it is necessary to develop more effective treatment methods such as chemical and photochemical degradation to remove completely contaminants.

For instance, advanced oxidation processes (AOPs) are proven to be very effective techniques for the degradation of a wide range of refractory pollutants in aqueous solution such as polymers [16], phenol [17], pesticides and dyes [18, 19]. These techniques are based on the generation of highly reactive radicals, such as hydroxyl radicals $\left({ }^{\circ} \mathrm{OH}\right)$ and hydroperoxyl radicals $\left(\mathrm{HO}_{2}{ }^{\circ}\right)$ which can react effectively with organic pollutants and reduce intermediate reaction species to $\mathrm{CO}_{2}$ and $\mathrm{H}_{2} \mathrm{O}$ without producing harmful by-products or sludges that must require further processing $[3,20]$.

Several researchers have studied the degradation of OTC (Fig. S1) by different AOPs methods such as ultraviolet (UV) $/ \mathrm{H}_{2} \mathrm{O}_{2}[19$, 21, 22], photo-Fenton [23], gamma radiation [11], anodic oxidation [24], pulse radiolysis [25], Ozone process [26] and photocatalysis $\mathrm{UV} / \mathrm{TiO}_{2}$ [27]. However, few studies focus on the mineralization and biodegradability of antibiotics using Fenton process.

In the present work, the degradation of OTC solution is investigated using Fenton process in a batch chemical reactor. The main aim of this study is to analyze how the degradation process of OTC can be affected by initial concentrations of OTC, $\mathrm{H}_{2} \mathrm{O}_{2}$, $\mathrm{Fe}^{2+}$, and $\mathrm{pH}$ as well as temperature and catalyst type. The mineralization and the biodegradability of antibiotic were also investigated.

\section{Experimental}

\subsection{Reagents}

OTC hydrochloride ( $>95 \%$ ) was purchased from Sigma-Aldrich and was used without further purification. $50 \%(\mathrm{w} / \mathrm{w})$ of hydrogen peroxide $\left(\mathrm{H}_{2} \mathrm{O}_{2}\right)$ was purchased from Merck (Germany) and was used by diluting it to $35 \%(\mathrm{w} / \mathrm{w})$. Analytical grade ferrous sulfate heptahydrate $\left(\mathrm{FeSO}_{4}\right.$. $\left.7 \mathrm{H}_{2} \mathrm{O}\right)$ was purchased from Biochem (France). Ferric sulfate $\left(\mathrm{Fe}_{2}\left(\mathrm{SO}_{4}\right)_{3}\right)$ with purity exceeding $90 \%$ was obtained from Prolabo (France). The $\mathrm{pH}$ of the solution was adjusted at the beginning with either dilute $\mathrm{H}_{2} \mathrm{SO}_{4}(0.5 \mathrm{~N})$ and $\mathrm{NaOH}(0.1 \mathrm{~N})$.

\subsection{Experimental Setup and Analysis}

All experiments were carried out in a double jacket $1 \mathrm{~L}$ stirred batch reactor as shown in Fig. 1. The reactor was covered with aluminum paper to prevent the degradation of OTC by the photo-Fenton system. The reactor was connected to a thermostatic bath to maintain a constant temperature of $25^{\circ} \mathrm{C}$. The reactor was also equipped with a magnetic stirrer to ensure a homogeneous reaction medium and a uniform concentration distribution in the reactor. A thermometer was placed in the reactor for temperature measurement and a port for sampling. The $\mathrm{pH}$ level was adjusted using a pH-meter (HANNA pH 209) at the onset of each experiment and no further $\mathrm{pH}$ adjustment was made during the reaction. The description and operating conditions of the reactor are given in Table 1.

For each experiment, OTC solution was prepared by dissolving $10 \mathrm{mg}$ of OTC in a $500 \mathrm{~mL}$ flask containing distilled water. The mixture was stirred at $600 \mathrm{rpm}$ for $20 \mathrm{~min}$ to make a homogenous stable solution. The desired concentration of $\mathrm{Fe}^{2+}$ was added to the solution of OTC. Specific amounts of $\mathrm{H}_{2} \mathrm{SO}_{4}$ or $\mathrm{NaOH}$ were injected for $\mathrm{pH}$ solution adjustment. The desired amount of $\mathrm{H}_{2} \mathrm{O}_{2}$ was poured into the reactor and the temperature kept constant at $25^{\circ} \mathrm{C}$.

Table 1. Reactor Operating Conditions

\begin{tabular}{lc}
\hline Item & Experimental operating range \\
\hline Reactor volume & $1 \mathrm{~L}$ \\
Temperature & $25-50^{\circ} \mathrm{C}$ \\
$\mathrm{pH}$ & $3-7$ \\
{$[\mathrm{OTC}]_{0}$} & $10-40 \mathrm{mg} / \mathrm{L}$ \\
{$\left[\mathrm{H}_{2} \mathrm{O}_{2}\right]_{0}$} & $70-200 \mathrm{mg} / \mathrm{L}$ \\
{$\left[\mathrm{Fe}^{2+}\right]_{0}$} & $2-10 \mathrm{mg} / \mathrm{L}$ \\
Treated volume & $500 \mathrm{~mL}$ \\
Agitation speed & $600 \mathrm{rpm}$ \\
\hline
\end{tabular}

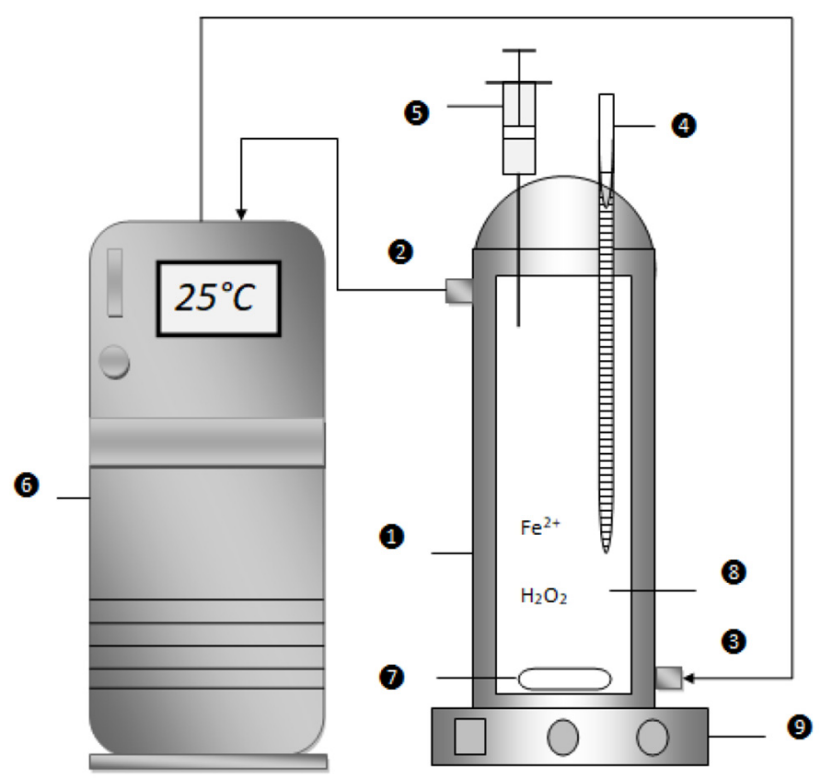

Fig. 1. Schematic diagram of the $\mathrm{H}_{2} \mathrm{O}_{2} / \mathrm{Fe}^{2+}$ system. Legend: 1. Chemical reactor, 2. Cooling or heating water outlet, 3. Cooling or heating water inlet, 4. Thermometer, 5. Syringe, 6. Circulating water bath, 7. Magnetic bar, 8. Reaction medium, 9. Magnetic stirrer. 
Samples were taken from the reactor at different time intervals and were immediately analyzed after being filtered in micropore disk (PES D.25 mm) of porosity of $0.45 \mu \mathrm{m}$. The degradation of OTC was evaluated upon measuring the absorbance of the treated solution with a spectrophotometer UV-VIS (SELECTA UV-2005). The maximum absorption wavelength is $353 \mathrm{~nm}$. A calibration curve relating the absorption signal to OTC concentration was established. The UV absorption spectrum of OTC is provided in Fig. S2. The percentage of OTC removal was calculated as follows:

$$
\text { OTC removal }=\frac{C_{o}-C_{t}}{C_{o}} \times 100 \%
$$

Where $C_{0}$ is the initial concentration of OTC and $C_{t}$ is the concentration of OTC at reaction time. COD was analyzed according to the method detailed by Thomas and Mazas [28], using a dichromate solution as oxidizer in a strong acid medium. Two $(2 \mathrm{~mL})$ of the test solution was mixed with dichromate reagent and digested for $2 \mathrm{~h}$ at $150^{\circ} \mathrm{C}$. The absorbance for the color change of dichromate solution at $\lambda=440 \mathrm{~mm}$ was determined with a UV-VIS spectrophotometer. If the sample contained hydrogen peroxide $\left(\mathrm{H}_{2} \mathrm{O}_{2}\right)$, to reduce interference in COD determination $\mathrm{pH}$ was increased to above 10 to decompose hydrogen peroxide to oxygen and water [29]. A cooled incubator (VELP Scientifica, FOC 120I) with BOD sensor was used to measure the value of BOD for five days $\left(\mathrm{BOD}_{5}\right)$.

\subsection{Reaction Mechanism}

The mechanism of the OTC degradation in the $\mathrm{H}_{2} \mathrm{O}_{2} / \mathrm{Fe}^{2+}$ and $\mathrm{H}_{2} \mathrm{O}_{2} / \mathrm{Fe}^{3+}$ process is based on the generation of ${ }^{\circ} \mathrm{OH}$ upon decomposition of $\mathrm{H}_{2} \mathrm{O}_{2}$ in presence of $\mathrm{Fe}^{2+}$ or $\mathrm{Fe}^{3+}$. These ${ }^{\circ} \mathrm{OH}$ are powerful oxidants, nonselective and highly reactive with organic matter. OTC reacts instantly with ${ }^{\circ} \mathrm{OH}$ and produces intermediate products which sequentially react with the ${ }^{\circ} \mathrm{OH}$ radicals and undergo a series of oxidation reactions up to total mineralization of the OTC into $\mathrm{H}_{2} \mathrm{O}$ and $\mathrm{CO}_{2}$ (Eq. (2)). OTC can also react with $\mathrm{HO}_{2}{ }^{\circ}$ and generate other byproducts as given in Eq. (3).

$$
\begin{array}{ccc}
\mathrm{OTC}+{ }^{\circ} \mathrm{OH} & \text { Products } & \mathrm{CO}_{2}+\mathrm{H}_{2} \mathrm{O} \\
\text { OTC }+\mathrm{HO}_{2} \cdot \text { Products } & \mathrm{CO}_{2}+\mathrm{H}_{2} \mathrm{O}
\end{array}
$$

\section{Results and Discussion}

Using the experimental conditions in Table 1, several experimental tests were conducted to investigate the effect of reaction temperature and of initial concentration of the reactants on the reactor performance to degrade the organic compound considered.

\subsection{Role of $\cdot \mathrm{OH}$ Radicals in OTC Degradation}

First, the results shown in Fig. 2 are very interesting and clearly exhibit the impact of $\mathrm{H}_{2} \mathrm{O}_{2}$ and $\mathrm{Fe}^{2+}$ in the degradation of OTC when they are used separately or combined. The contribution of $\mathrm{Fe}^{2+}$ in the generation of ${ }^{\circ} \mathrm{OH}$ radicals leads to an oxidation of $90.67 \%$ of OTC compared to $12.22 \%$ when $\mathrm{H}_{2} \mathrm{O}_{2}$ is alone. Hence, this result highlights the significant role of ${ }^{\circ} \mathrm{OH}$ radicals in the elimination of OTC in $\mathrm{H}_{2} \mathrm{O}_{2} / \mathrm{Fe}^{2+}$ process. The degradation rate of OTC was much higher in $\mathrm{H}_{2} \mathrm{O}_{2} / \mathrm{Fe}^{2+}$ system than in $\mathrm{H}_{2} \mathrm{O}_{2}$ alone, which is probably due to the production of substantial amount of highly reactive radicals $\left({ }^{\circ} \mathrm{OH}\right)$ that are mainly can disintegrate molecules of OTC antibiotic as ${ }^{\circ} \mathrm{OH}$ have a high oxidation potential $\left(\mathrm{E}^{0}=2.8 \mathrm{~V}\right)$.

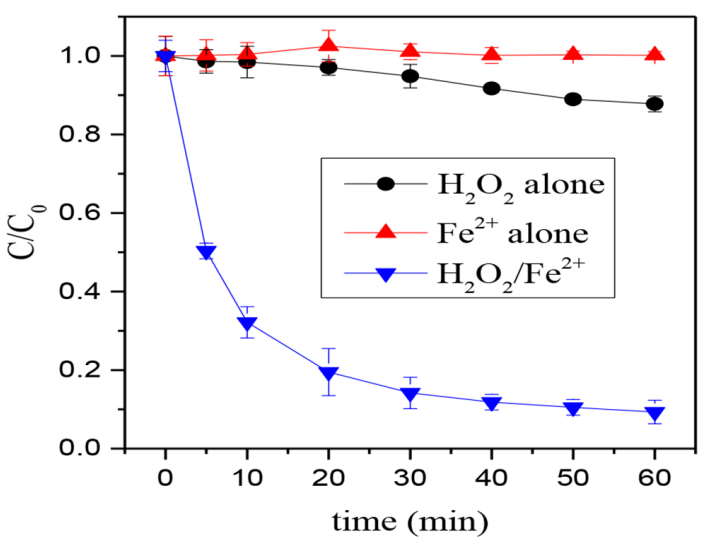

Fig. 2. Degradation of OTC by $\mathrm{H}_{2} \mathrm{O}_{2}$ or $\mathrm{Fe}^{2+}$ alone and $\mathrm{H}_{2} \mathrm{O}_{2} / \mathrm{Fe}^{2+}$ system, with $[\mathrm{OTC}]_{0}=20 \mathrm{mg} / \mathrm{L},\left[\mathrm{H}_{2} \mathrm{O}_{2}\right]_{0}=200 \mathrm{mg} / \mathrm{L},\left[\mathrm{Fe}^{2+}\right]_{0}=$ $5 \mathrm{mg} / \mathrm{L}, \mathrm{pH}=3, \mathrm{~T}=25^{\circ} \mathrm{C}$.

\subsection{Effect of Initial $\mathrm{H}_{2} \mathrm{O}_{2}$ Concentration}

Hydrogen peroxide dosage is an important factor to evaluate the performance of Fenton process. Thus, the concentration of $\mathrm{H}_{2} \mathrm{O}_{2}$ was varied from $70 \mathrm{mg} / \mathrm{L}$ to $200 \mathrm{mg} / \mathrm{L}$ for an invariant initial concentration of OTC and ferrous ion of $20 \mathrm{mg} / \mathrm{L}$ and $5 \mathrm{mg} / \mathrm{L}$, respectively. The lowest concentration of $\mathrm{H}_{2} \mathrm{O}_{2}(70 \mathrm{mg} / \mathrm{L})$ that was required to start the OTC degradation was based on the necessary stoichiometric ratios of the reaction to completely oxidize $20 \mathrm{mg} / \mathrm{L}$ of OTC according to the reaction below:

$$
\mathrm{C}_{22} \mathrm{H}_{24} \mathrm{~N}_{2} \mathrm{O}_{9}+52 \mathrm{H}_{2} \mathrm{O}_{2} \rightarrow 22 \mathrm{CO}_{2}+63 \mathrm{H}_{2} \mathrm{O}+2 \mathrm{HNO}_{3}
$$

Plots in Fig. 3(a) describe the degradation of OTC at various initial concentrations of $\mathrm{H}_{2} \mathrm{O}_{2}$ and show that the rate of degradation of OTC increases with higher concentration of $\mathrm{H}_{2} \mathrm{O}_{2}$. In the presence of $\mathrm{Fe}^{2+}$, hydrogen peroxide decomposes much more effectively and produces more free radicals which can immediately react with OTC. It is obvious that with higher $\mathrm{H}_{2} \mathrm{O}_{2}$ concentration, there is a higher chance to get more ${ }^{\circ} \mathrm{OH}$ in the reacting system.

However, no enhancement was observed when the initial concentration of $\mathrm{H}_{2} \mathrm{O}_{2}$ exceeded $150 \mathrm{mg} / \mathrm{L}$ beyond a reaction time of $40 \mathrm{~min}$. This result is quite interesting. It is due to an excess of hydrogen peroxide in the solution which leads to a scavenging phenomenon on ${ }^{\circ} \mathrm{OH}$ as shown in Eq. (5).

$$
\mathrm{H}_{2} \mathrm{O}_{2}+{ }^{\cdot} \mathrm{OH} \rightarrow \mathrm{HO}_{2}{ }^{\cdot}+\mathrm{H}_{2} \mathrm{O}
$$


This reaction produces more $\mathrm{HO}_{2}{ }^{\cdot}$ that have an oxidation potential $\mathrm{E}^{0}$ of $1.7 \mathrm{~V}$. It is therefore less reactive than ${ }^{\circ} \mathrm{OH}$ radicals and results in lowering the consumption rate of OTC. The highest consumption of $\mathrm{H}_{2} \mathrm{O}_{2}$ occurred during the first $30 \mathrm{~min}$ of degradation for all tests with different $\mathrm{H}_{2} \mathrm{O}_{2}$ initial concentrations. Elsewhere, Subramonian et al. [30] observed that a drop of COD removal occurred during the treatment of pulp and paper mill effluent when higher $\mathrm{H}_{2} \mathrm{O}_{2}$ was used due to the scavenging effect.

\subsection{Effect of Initial Catalyst $\left(\mathrm{Fe}^{2+}\right)$ Concentration}

Further, the presence of the catalyst in Fenton process for the generation of ${ }^{\circ} \mathrm{OH}$ plays an important role as shown in the reaction below:

$$
\mathrm{Fe}^{2+}+\mathrm{H}_{2} \mathrm{O}_{2} \rightarrow \mathrm{Fe}^{3+}+{ }^{\cdot} \mathrm{OH}+\mathrm{OH}^{-}
$$

In this work, the impact of the catalyst $\mathrm{Fe}^{2+}$ was studied over the range of 2 to $10 \mathrm{mg} / \mathrm{L}$. In fact, $\mathrm{Fe}^{2+}$ favors the generation of more ${ }^{\circ} \mathrm{OH}$ radicals which therefore improves the degradation of OTC, which is confirmed by plots shown in Fig. 3(b) for higher concentration of $\mathrm{Fe}^{2+}$. However, beyond 30 min of treatment, the degradation rate of OTC was lowered for $\mathrm{Fe}^{2+}$ initial concentration of $10 \mathrm{mg} / \mathrm{L}$ and the highest degradation efficiency achieved was $90.82 \%$ at $\mathrm{Fe}^{2+}=5 \mathrm{mg} / \mathrm{L}$. In fact, the reduction of OTC removal during the increase of the concentration of $\mathrm{Fe}^{2+}$ from $5 \mathrm{mg} / \mathrm{L}$ can be explained by the setting up of a parasitic reaction consuming the ${ }^{\circ} \mathrm{OH}$ (Eq. (7)). The rate of this reaction becomes important and will compete with the degradation of the OTC. On the other hand, the $\mathrm{Fe}^{3+}$ ions formed at higher concentrations can react with hydrogen peroxide (Eq. (8)), and consequently reduce the degradation efficiency. Similar observations have been reported by some publications at higher concentration of $\mathrm{Fe}^{2+}[29,31,32]$.

$$
\begin{gathered}
\mathrm{Fe}^{2+}+\cdot \mathrm{OH} \rightarrow \mathrm{Fe}^{3+}+\mathrm{OH}^{-} \\
\mathrm{Fe}^{3+}+\mathrm{H}_{2} \mathrm{O}_{2} \rightarrow \mathrm{Fe}^{2+}+\mathrm{HO}_{2}^{\cdot}+\mathrm{H}^{+}
\end{gathered}
$$

\subsection{Effect of Initial OTC Concentration}

The dependence of OTC degradation on its initial concentration has been investigated as well over an interval between 10 and $40 \mathrm{mg} / \mathrm{L}$ with an optimum $\mathrm{H}_{2} \mathrm{O}_{2}$ concentration of $150 \mathrm{mg} / \mathrm{L}$ and $\mathrm{Fe}^{2+}$ concentration of $5 \mathrm{mg} / \mathrm{L}$.

The results in Fig. 3(c) show that the OTC degradation rate decays starting from high initial OTC concentrations. For instance, with initial OTC concentrations of $10,20,30$ and $40 \mathrm{mg} / \mathrm{L}$, the removal efficiency achieved after $60 \mathrm{~min}$ were 90.95, 90.82, 88.47 and $85.27 \%$, respectively. Keeping the operating conditions invariant, the OTC degradation rate decreased much faster as the initial OTC concentration is augmented. However, high OTC concentrations resulted in more intermediate products which compete with OTC to react with ${ }^{\circ} \mathrm{OH}$ and can also become limiting reagents. Consequently, a reduction of the rate constants was obtained.

Moreover, the reduction in degradation yield for an initial concentration of OTC can be related to a similar amount of ${ }^{\circ} \mathrm{OH}$ radicals formed in all solutions considered. These results are in accordance with the data reported by Chekir et al. [33], who studied the degrada- tion of spiramycine antibiotic by $\mathrm{UV} / \mathrm{TiO}_{2}$ under solar light. The degradation efficiency obtained in this study is quite similar to that of Chekir et al. [33]. In another study, Hoseini et al. [34] investigated the degradation of TC antibiotic by means of sonocatalytic system for initial concentrations of 25, 50, 75 and $100 \mathrm{mg} / \mathrm{L}$ and the removal rates reported were $70.1,65.3,58.3$ and $50 \%$, respectively.
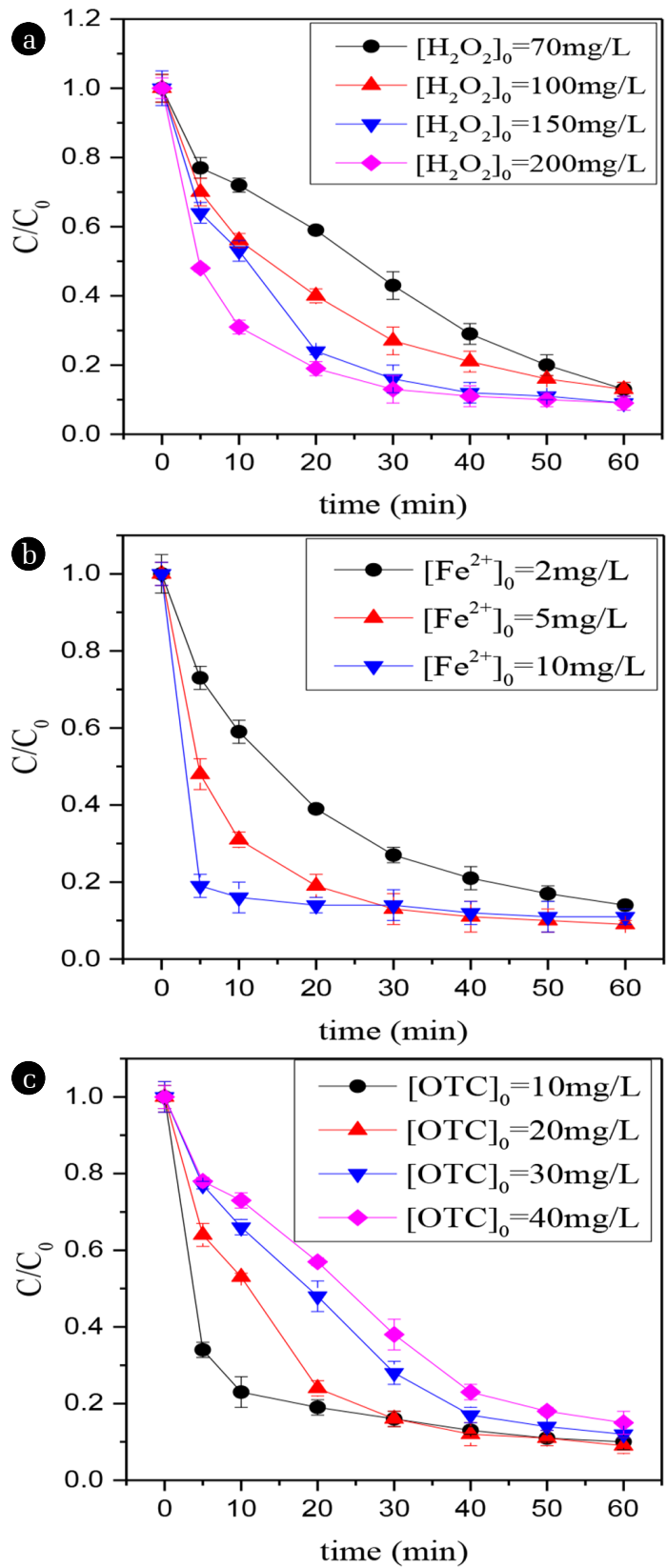

Fig. 3. Effect of different operating conditions on OTC degradation (a: initial $\mathrm{H}_{2} \mathrm{O}_{2}$ concentration with $[\mathrm{OTC}]_{0}=20 \mathrm{mg} / \mathrm{L},\left[\mathrm{Fe}^{2+}\right]_{0}$ $=5 \mathrm{mg} / \mathrm{L}, \mathrm{b}$ : initial $\mathrm{Fe}^{2+}$ concentration with $[\mathrm{OTC}]_{0}=20 \mathrm{mg} / \mathrm{L}$, $\left[\mathrm{H}_{2} \mathrm{O}_{2}\right]_{0}=200 \mathrm{mg} / \mathrm{L}$, c: initial OTC concentration with $\left[\mathrm{H}_{2} \mathrm{O}_{2}\right]_{0}$ $\left.=150 \mathrm{mg} / \mathrm{L},\left[\mathrm{Fe}^{2+}\right]_{0}=5 \mathrm{mg} / \mathrm{L}\right)$. All tests were carried out at $\mathrm{pH}=3$ and $\mathrm{T}=25^{\circ} \mathrm{C}$. 


\subsection{Effect of Temperature}

Three experimental tests were performed at temperatures of 25, 40 and $50^{\circ} \mathrm{C}$ to evaluate the reaction thermal effect on OTC degradation. Plots in Fig. 4 demonstrate that there is hardly no degradation of OTC when no $\mathrm{H}_{2} \mathrm{O}_{2} / \mathrm{Fe}^{2+}$ was utilized. Thermal energy $\left(40\right.$ and $50^{\circ} \mathrm{C}$ ) alone did not break OTC molecules. The tests show that OTC degradation is only effective when hydrogen peroxide $\mathrm{H}_{2} \mathrm{O}_{2}$ is mingled with ferrous iron $\mathrm{Fe}^{2+}$.

Besides, plots in Fig. 4 show also that the degradation rate of OTC is favored by increasing the temperature. In the first stage, the degradation efficiency after $20 \mathrm{~min}$ of reaction increases from 76 to $89 \%$ for a temperature of 25 to $50^{\circ} \mathrm{C}$. The oxidation reaction of the OTC by the $\mathrm{OH}$ is therefore favored by an addition of thermal energy. In fact, the solution temperature influences the electron transfer and the mass transfer rates, which in turn influences the rate of generation of ${ }^{\circ} \mathrm{OH}$ and their reactivity with OTC. In the second stage (up to $20 \mathrm{~min}$ ), the degradation rate slowed down due to a lower production rate of $\mathrm{Fe}^{2+}$ from $\mathrm{Fe}^{3+}$ [35] and the degradation efficiency slightly improved. The final degradation efficiency achieved after 60 min were 90.82, 92.23 and $92.88 \%$ for the temperature of 25,40 and $50^{\circ} \mathrm{C}$, respectively. However, because of the rise in operating cost for a low gain achieved by increasing the temperature from 25 to $50^{\circ} \mathrm{C}$, ambient temperature seems the best setting to apply to an OTC system. Similar observations were reported by Aygun et al. [36] in the first and the second stage of treatment using Fenton process.

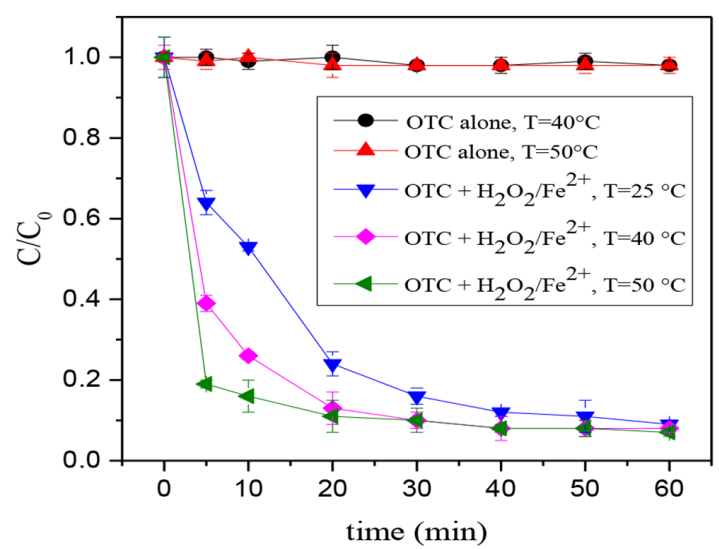

Fig. 4. OTC degradation versus time for different reaction temperatures, with $[\mathrm{OTC}]_{0}=20 \mathrm{mg} / \mathrm{L},\left[\mathrm{H}_{2} \mathrm{O}_{2}\right]_{0}=150 \mathrm{mg} / \mathrm{L},\left[\mathrm{Fe}^{2+}\right]_{0}=5 \mathrm{mg} / \mathrm{L}$, $\mathrm{pH}=3$.

The apparent rate constants $\left(\mathrm{k}_{\mathrm{app}}\right)$ of the degradation of OTC obtained in the first OTC degradation stage at 25,40 and $50^{\circ} \mathrm{C}$ were $0.068,0.145$ and $0.213 \mathrm{~min}^{-1}$, respectively. Accordingly, the apparent activation energy $\left(\mathrm{E}_{\mathrm{app}}\right)$ of the OTC degradation reaction in a Fenton process was determined using the Arrhenius equation as follows:

$$
\ln k_{a p p}=\ln A-\left(\frac{E_{a p p}}{R T}\right)
$$

Where $A$ is the frequency factor, $E_{\text {app }}$ is the apparent activation energy, $R$ is the gas constant and $T$ is the temperature. Fig. S3 shows a linear plot of $\ln \mathrm{k}_{\text {app }}$ versus $1 / \mathrm{T}$ with a determination coefficient greater than 0.99. The apparent activation energy $\mathrm{E}_{\mathrm{app}}$, obtained from the Arrhenius plot (Fig. S3) is $36.58 \mathrm{~kJ} / \mathrm{mol}$. This result indicates that the degradation of an aqueous solution of OTC by Fenton process requires low activation energy and therefore it can be easily achieved. In this context, the results reported by Karatas et al. [37] are in accordance with the data obtained in this study.

\subsection{Effect of Initial pH Solution}

Several AOPs studies [16] which were conducted on wastewater treatment concluded that the determination of $\mathrm{pH}$ of a solution being treated is a key variable to investigate. In particular, the degradation of organic compounds by Fenton process is generally carried out in an acidic $\mathrm{pH}$ medium to preserve the aqueous $\mathrm{Fe}^{2+}$ ions in the solution.

In fact, solutions with initial $\mathrm{pH}$ between 1 and 7 were made to investigate the acidity effect on OTC degradation in a Fenton process. Each solution consists of OTC, $\mathrm{H}_{2} \mathrm{O}_{2}$ and $\mathrm{Fe}^{2+}$ which initial respective concentrations are $20 \mathrm{mg} / \mathrm{L}, 150 \mathrm{mg} / \mathrm{L}$ and 5 $\mathrm{mg} / \mathrm{L}$.

Plots in Fig. 5 show that for solutions with a $\mathrm{pH}$ values from 1 to 7 , the OTC degradation yield in the Fenton process are 68.72, $77.37,90.82$, 90.63, 80.75, 68.62 and $46.26 \%$, respectively. The experimental tests demonstrate that the OTC degradation rate increases for solutions which $\mathrm{pH}$ is less below a threshold of about 3.5 which can characterized as an optimum $\mathrm{pH}$ for solutions to be treated in the Fenton process. For $\mathrm{pH}$ values below 3, the reaction of hydrogen peroxide with $\mathrm{Fe}^{2+}$ is seriously affected causing the reduction in hydroxyl radicals production. At $\mathrm{pH} 1$ and 2, the low degradation may be due to the $\cdot \mathrm{OH}$ scavenging of $\mathrm{H}^{+}$ions (Eq. (10)) [38]. Moreover, the $\mathrm{H}_{2} \mathrm{O}_{2}$ gets solvated in the presence of high concentration of $\mathrm{H}^{+}$ion to form stable oxonium ion $\mathrm{H}_{3} \mathrm{O}_{2}{ }^{+}$. An oxonium ion makes hydrogen peroxide electrophilic to enhance its stability and presumably to reduce substantially the reactivity with ferrous ion [39]. On the other hand, the drop in OTC degradation efficiency at $\mathrm{pH}>4$ may be due to the precipitation of dissolved

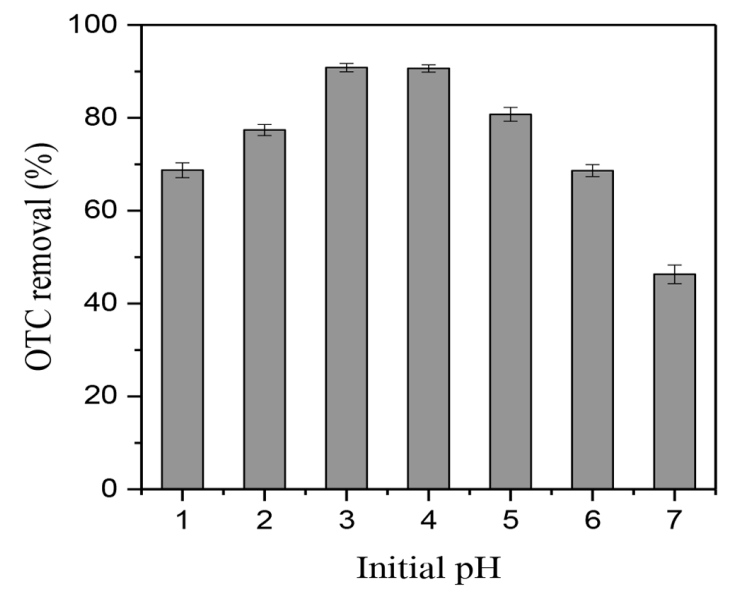

Fig. 5. OTC degradation efficiency versus initial $\mathrm{pH}$ solution, with [OTC] $=20 \mathrm{mg} / \mathrm{L},\left[\mathrm{H}_{2} \mathrm{O}_{2}\right]_{0}=150 \mathrm{mg} / \mathrm{L},\left[\mathrm{Fe}^{2+}\right]_{0}=5 \mathrm{mg} / \mathrm{L}, \mathrm{T}=25^{\circ} \mathrm{C}$. 
iron in presence of high concentration of $\mathrm{OH}^{-}$ions (Eq. (11) and (12)), and a decrease of $\mathrm{H}_{2} \mathrm{O}_{2}$ decomposition into hydroxyl radicals. In addition, another study [38] reported that higher $\mathrm{pH}$ in solutions caused the oxidation potential of hydroxyl radical to decrease.

$$
\begin{gathered}
\cdot \mathrm{OH}+\mathrm{H}^{+}+\mathrm{e}^{-} \rightarrow \mathrm{H}_{2} \mathrm{O} \\
\mathrm{Fe}^{2+}+2 \mathrm{OH}^{-} \rightarrow \mathrm{Fe}(\mathrm{OH})_{2} \\
\mathrm{Fe}^{3+}+3 \mathrm{OH}^{-} \rightarrow \mathrm{Fe}(\mathrm{OH})_{3}
\end{gathered}
$$

\subsection{Effect of Type of Catalyst $\left(\mathrm{Fe}^{2+}, \mathrm{Fe}^{3+}\right)$}

Fig. 6 shows a comparison between two systems of degradation, Fenton system $\left(\mathrm{H}_{2} \mathrm{O}_{2} / \mathrm{Fe}^{2+}\right)$ and Fenton-like system $\left(\mathrm{H}_{2} \mathrm{O}_{2} / \mathrm{Fe}^{3+}\right)$ that were operated using identical operating conditions (OTC = $\left.20 \mathrm{mg} / \mathrm{L}, \mathrm{H}_{2} \mathrm{O}_{2}=150 \mathrm{mg} / \mathrm{L}, \mathrm{Fe}^{2+}=\mathrm{Fe}^{3+}=5 \mathrm{mg} / \mathrm{L}\right)$. The degradation yield achieved was $90.82 \%$ and $88.20 \%$ in Fenton and Fenton-like systems, respectively. But, in the first $30 \mathrm{~min}$, the degradation rate in the Fenton process was much faster than that in the Fenton-like process. This can be related to OTC oxidation having much more affinity for ${ }^{\circ} \mathrm{OH}$ radicals in the Fenton process according to Eq. (3) which has a rate constant of $70 \mathrm{Lmol}^{-1} \mathrm{~s}^{-1}$. However, the oxidation in the Fenton-like process is much more favored with $\mathrm{HO}_{2}{ }^{\circ}$ which has less power of oxidation than ${ }^{\circ} \mathrm{OH}$ radicals. Moreover, the rate constant $\left(0.02 \mathrm{Lmol}^{-1} \mathrm{~s}^{-1}\right)$ of production of $\mathrm{HO}_{2}{ }^{\circ}$ is very slow as defined in Eq. (8).

From $30 \mathrm{~min}$ onwards to the reaction end, the rate of OTC degradation is almost the same in both processes. Similar observations were reported by Wang et al. [40] who studied the decolourisation of wastewater from an azo dye in Fenton and Fenton-like processes.

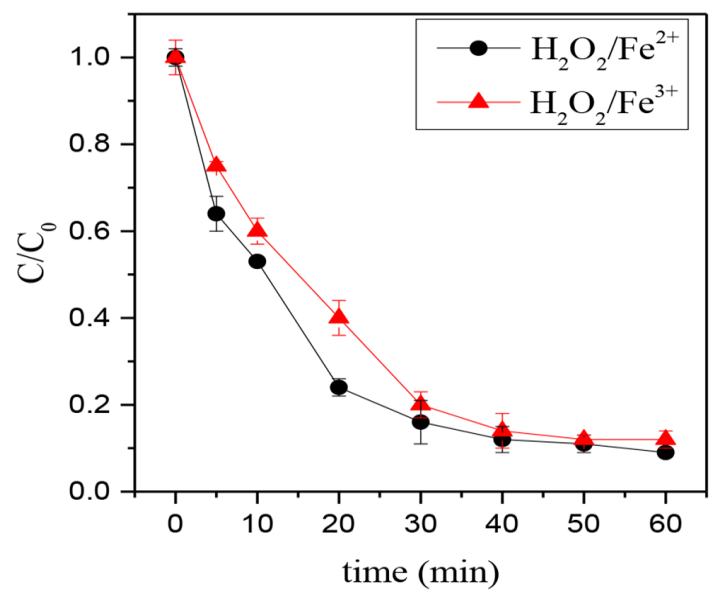

Fig. 6. Performance of Fenton and Fenton-like processes for OTC degradation, with $[\mathrm{OTC}]_{0}=20 \mathrm{mg} / \mathrm{L},\left[\mathrm{H}_{2} \mathrm{O}_{2}\right]_{0}=150 \mathrm{mg} / \mathrm{L},\left[\mathrm{Fe}^{2+}\right]_{0}=$ $5 \mathrm{mg} / \mathrm{L},\left[\mathrm{Fe}^{3+}\right]_{0}=5 \mathrm{mg} / \mathrm{L}, \mathrm{pH}=3, \mathrm{~T}=25^{\circ} \mathrm{C}$.

\subsection{Mineralization and Biodegradability of Treated OTC Solution}

To evaluate the effectiveness of mineralization of OTC using Fenton process, COD was investigated at optimal operating conditions found for OTC degradation. The effect of initial antibiotic concen- tration on the COD reduction was studied by considering initial OTC concentration of 20, 40, 60 and $80 \mathrm{mg} / \mathrm{L}$ which correspond to initial COD of 31.70, 63.25, 90.56 and $125.29 \mathrm{mg} / \mathrm{L}$, respectively. The percent of COD reduction achieved after $60 \mathrm{~min}$ of treatment were found to be 78.35, 70.13, 63.80 and 51.27\% (figure not shown). These results show that COD removal decreases with higher initial COD, which can be explained by the increasing of byproducts that slow down the mineralization. In the other hand, the effect of initial $\mathrm{pH}$ solution was also examined in the range of 2 to 5 for initial OTC concentration of $20 \mathrm{mg} / \mathrm{L}$. The highest CODs removal percent obtained were 78.35 and $76.62 \%$ for initial $\mathrm{pH}$ of 3 and 4, respectively. As plotted in Fig. S4, the COD removal decreases progressively when the initial $\mathrm{pH}$ is higher than 3 , this is may be due to a lower dissolved iron that can be responsible for the decomposition of $\mathrm{H}_{2} \mathrm{O}_{2}$ into hydroxyl radicals. These results confirm an optimum $\mathrm{pH}$ of 3 for the Fenton process.

As shown in Fig. 7, the rate of COD reduction was quite fast in the first $20 \mathrm{~min}$ (65.37\% of COD removed) and then slows down gradually until the end of the reaction. This trend may be due to a rapid consumption of $\mathrm{Fe}^{2+}$ at the reaction beginning and the generation of large amount of hydroxyl radicals which are mainly responsible on disintegrating the organic compound. Then, the OTC degradation rate remained slow because of a decrease in hydroxyl radicals and the mineralization was achieved with other species radicals such as the hydroperoxyl radical which has a low oxidation power than hydroxyl radical. Fig. 7 also shows that the ratio of $\mathrm{BOD}_{5} / \mathrm{COD}$ increased significantly from 0.04 to 0.36. This increment demonstrates clearly that the treated OTC product has a higher biodegradability compared to OTC before mineralization. The ratio of biodegradability $\mathrm{BOD}_{5} / \mathrm{COD}$ is 0.36 and it is considered adequate for biological treatment as wastewater is considered biodegradable if this ratio is 0.4 [41].

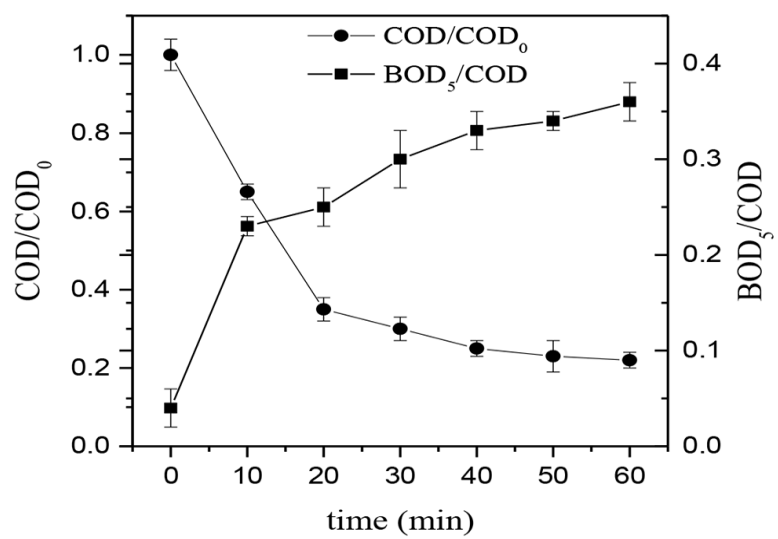

Fig. 7. Mineralization and biodegradability of treated OTC solution with $[\mathrm{OTC}]_{0}=20 \mathrm{mg} / \mathrm{L},\left[\mathrm{H}_{2} \mathrm{O}_{2}\right]_{0}=150 \mathrm{mg} / \mathrm{L},\left[\mathrm{Fe}^{2+}\right]_{0}=5 \mathrm{mg} / \mathrm{L}$, $\mathrm{pH}=3, \mathrm{~T}=25^{\circ} \mathrm{C}$.

\section{Conclusions}

Oxidation and molecular degradation of OTC were investigated under different operating conditions in Fenton and Fenton-like 
processes for $60 \mathrm{~min}$ of reaction. An OTC degradation efficiency of $12.22 \%$ was obtained when $\mathrm{H}_{2} \mathrm{O}_{2}$ was used alone in the Fenton process. However, the degradation rate of OTC in the Fenton process $\left(\mathrm{H}_{2} \mathrm{O}_{2} / \mathrm{Fe}^{2+}\right)$ and Fenton-like process $\left(\mathrm{H}_{2} \mathrm{O}_{2} / \mathrm{Fe}^{3+}\right)$ was much higher, with a removal efficiency of $90.82 \%$ and $88.20 \%$, respectively. An increase of OTC initial concentration lowered the degradation efficiency and an excess of $\mathrm{H}_{2} \mathrm{O}_{2}$ can also impede removal efficiency of OTC. Besides, the initial $\mathrm{pH}$ is an important parameter in the degradation of OTC. A high degradation rate was obtained for a $\mathrm{pH}$ of 3 confirming the optimum $\mathrm{pH}$ value for Fenton process. The highest value of $90.95 \%$ removal efficiency was achieved in the Fenton process operated with a ratio $\mathrm{H}_{2} \mathrm{O}_{2} / \mathrm{OTC}$ of $15, \mathrm{Fe}^{2+}$ concentration of $5 \mathrm{mg} / \mathrm{L}$ and $\mathrm{pH}$ value of 3 at an ambient temperature of $25^{\circ} \mathrm{C}$. Under the same operating conditions, the highest percent of COD removal achieved was $78.35 \%$. A remarkable enhancement in OTC biodegradability from 0.04 to 0.36 was also achieved in 60 min reaction time. This study indicated that Fenton process can be used for pretreatment of wastewater contaminated by OTC before a biological treatment.

\section{Acknowledgments}

The authors would like to thank the Ministry of Higher Education in Algeria for the financial support.

\section{Nomenclature}

$\begin{array}{ll}\mathrm{E}_{\text {app }} & \text { Apparent activation energy }(\mathrm{kJ} / \mathrm{mol}) \\ \mathrm{k}_{\text {app }} & \text { Apparent rate constants }(\mathrm{min}-1) \\ \mathrm{A} & \text { Frequency factor } \\ \mathrm{E}^{0} & \text { Oxidation potential }(\mathrm{V}) \\ \mathrm{OTC} & \text { OTC antibiotic } \\ \mathrm{pH} & \text { Hydrogen potential of the solution } \\ \mathrm{R} & \text { Gas constant }(8,314 \mathrm{~J} \text { mol- } 1 \mathrm{~K}-1) \\ \mathrm{T} & \text { Temperature of the solution }\left({ }^{\circ} \mathrm{C}\right) \\ \mathrm{TCs} & \text { Tetracycline antibiotics group }\end{array}$

\section{References}

1. Khetan SK, Collins TJ. Human pharmaceuticals in the aquatic environment: A challenge to green chemistry. Chem. Rev. 2007;107:2319-2364.

2. Lillenberg M, Yurchenko S, Kipper K, et al. Presence of fluoroquinolones and sulfonamides in urban sewage sludge and their degradation as a result of composting. Int. J. Environ. Sci. Technol. 2010;7:307-312.

3. Klavarioti M, Mantzavinos D, Kassinos D. Removal of residual pharmaceuticals from aqueous systems by advanced oxidation processes. Environ. Int. 2009;35:402-417.

4. Laera G, Cassano D, Lopez A, et al. Removal of organics and degradation products from industrial wastewater by a membrane bioreactor integrated with ozone or $\mathrm{UV} / \mathrm{H}_{2} \mathrm{O}_{2}$ treatment. Environ. Sci. Technol. 2011;46:1010-1018.
5. Gupta SK, Gupta SK, Hung Y-T. Treatment of pharmaceutical wastes. In: Wang LK, Hung YT, Howard HL, Yapijakis C, eds. Waste treatment in the process industries. CRC Taylor and Francis; 2006. p. 167-233.

6. Schröder HF. Substance-specific detection and pursuit of non-eliminable compounds during biological treatment of waste water from the pharmaceutical industry. Waste Manage. 1999;19:111-123.

7. Sreekanth D, Sivaramakrishna D, Himabindu V, Anjaneyulu Y. Thermophilic treatment of bulk drug pharmaceutical industrial wastewaters by using hybrid up flow anaerobic sludge blanket reactor. Bioresour. Technol. 2009;100:2534-2539.

8. Figueroa RA, Leonard A, MacKay AA. Modeling tetracycline antibiotic sorption to clays. Environ. Sci. Technol. 2004;38:476-483.

9. López-Peñalver JJ, Sánchez-Polo M, Gómez-Pacheco CV, Rivera -Utrilla J. Photodegradation of tetracyclines in aqueous solution by using UV and $\mathrm{UV} / \mathrm{H}_{2} \mathrm{O}_{2}$ oxidation processes. J. Chem. Technol. Biotechnol. 2010;85:1325-1333.

10. Palominos RA, Mondaca MA, Giraldo A, Peñuela G, Pérez-Moya $\mathrm{M}$, Mansilla $\mathrm{HD}$. Photocatalytic oxidation of the antibiotic tetracycline on $\mathrm{TiO}_{2}$ and $\mathrm{ZnO}$ suspensions. Catal. Today 2009;144: 100-105.

11. López Peñalver JJ, Gómez Pacheco CV, Sánchez Polo M, Rivera Utrilla J. Degradation of tetracyclines in different water matrices by advanced oxidation/reduction processes based on gamma radiation. J. Chem. Technol. Biotechnol. 2013;88:1096-1108.

12. Kolar B, Arnuš L, Jeretin B, Gutmaher A, Drobne D, Durjava MK. The toxic effect of oxytetracycline and trimethoprim in the aquatic environment. Chemosphere 2014;115:75-80.

13. Feng L, van Hullebusch ED, Rodrigo MA, Esposito G, Oturan MA. Removal of residual anti-inflammatory and analgesic pharmaceuticals from aqueous systems by electrochemical advanced oxidation processes. A review. Chem. Eng. J. 2013;228:944-964.

14. Mboula VM, Hequet V, Gru Y, Colin R, Andres Y. Assessment of the efficiency of photocatalysis on tetracycline biodegradation. J. Hazard. Mater. 2012;209:355-364.

15. Oller I, Malato S, Sánchez-Pérez J. Combination of advanced oxidation processes and biological treatments for wastewater decontamination - A review. Sci. Total Environ. 2011;409: 4141-4166.

16. Hamad D, Mehrvar M, Dhib R. Experimental study of polyvinyl alcohol degradation in aqueous solution by $\mathrm{UV} / \mathrm{H}_{2} \mathrm{O}_{2}$ process. Polym. Degrad. Stab. 2014;103:75-82.

17. Maleki A, Mahvi A, Mesdaghinia A, Naddafi K. Degradation and toxicity reduction of phenol by ultrasound waves. Bull. Chem. Soc. Ethiop. 2007;21:33-38.

18. Stock NL, Peller J, Vinodgopal K, Kamat PV. Combinative sonolysis and photocatalysis for textile dye degradation. Environ. Sci. Technol. 2000;34:1747-1750.

19. Low FCF, Wu TY, Teh CY, Juan JC, Balasubramanian N. Investigation into photocatalytic decolorisation of CI Reactive Black 5 using titanium dioxide nanopowder. Color. Technol. 2012;128:44-50.

20. He X, Mezyk SP, Michael I, Fatta-Kassinos D, Dionysiou DD. Degradation kinetics and mechanism of $\beta$-lactam antibiotics by the activation of $\mathrm{H}_{2} \mathrm{O}_{2}$ and $\mathrm{Na}_{2} \mathrm{~S}_{2} \mathrm{O}_{8}$ under UV-254 nm 
irradiation. J. Hazard. Mater. 2014;279:375-383.

21. Liu Y, He X, Fu Y, Dionysiou DD. Degradation kinetics and mechanism of oxytetracycline by hydroxyl radical-based advanced oxidation processes. Chem. Eng. J. 2016;284:1317-1327.

22. Yuan F, Hu C, Hu X, Wei D, Chen Y, Qu J. Photodegradation and toxicity changes of antibiotics in $\mathrm{UV}$ and $\mathrm{UV} / \mathrm{H}_{2} \mathrm{O}_{2}$ process. J. Hazard. Mater. 2011;185:1256-1263.

23. Pereira JH, Queirós DB, Reis AC, et al. Process enhancement at near neutral $\mathrm{pH}$ of a homogeneous photo-Fenton reaction using ferricarboxylate complexes: Application to oxytetracycline degradation. Chem. Eng. J. 2014;253:217-228.

24. Fernandes A, Oliveira C, Pacheco MJ, Ciríaco L, Lopes A. Anodic oxidation of oxytetracycline: Influence of the experimental conditions on the degradation rate and mechanism. J. Electrochem. Sci. Eng. 2014;4:203-213.

25. Jeong J, Song W, Cooper WJ, Jung J, Greaves J. Degradation of tetracycline antibiotics: Mechanisms and kinetic studies for advanced oxidation/reduction processes. Chemosphere 2010;78:533-540.

26. Li K, Yediler A, Yang M, Schulte-Hostede S, Wong MH. Ozonation of oxytetracycline and toxicological assessment of its oxidation by-products. Chemosphere 2008;72:473-478.

27. Pereira JH, Vilar VJ, Borges MT, González O, Esplugas S, Boaventura RA. Photocatalytic degradation of oxytetracycline using $\mathrm{TiO}_{2}$ under natural and simulated solar radiation. Sol. Energy 2011;85:2732-2740.

28. Thomas O, Mazas N. La mesure de la demande chimique en oxygène dans les milieux faiblement pollués. Analusis 1986;14:300-302.

29. Elmolla E, Chaudhuri M. Optimization of Fenton process for treatment of amoxicillin, ampicillin and cloxacillin antibiotics in aqueous solution. J. Hazard. Mater. 2009;170:666-672.

30. Subramonian W, Wu TY, Chai S-P. Photocatalytic degradation of industrial pulp and paper mill effluent using synthesized magnetic $\mathrm{Fe}_{2} \mathrm{O}_{3}-\mathrm{TiO}_{2}$ : Treatment efficiency and characterizations of reused photocatalyst. J. Environ. Manage. 2017;187:298-310.
31. Mansour D, Fourcade F, Bellakhal N, Dachraoui M, Hauchard D, Amrane A. Biodegradability improvement of sulfamethazine solutions by means of an electro-Fenton process. Water Air Soil Pollut. 2012;223:2023-2034.

32. Perez M, Torrades F, Domenech X, Peral J. Fenton and photo-Fenton oxidation of textile effluents. Water Res. 2002;36: 2703-2710.

33. Chekir N, Laoufi NA, Bentahar F. Spiramycin photocatalysis under artificial UV radiation and natural sunlight. Desalin. Water Treat. 2014;52:6832-6839.

34. Hoseini M, Safari GH, Kamani H, Jaafari J, Ghanbarain M, Mahvi AH. Sonocatalytic degradation of tetracycline antibiotic in aqueous solution by sonocatalysis. Toxicol. Environ. Chem. 2013;95:1680-1689.

35. Ramirez JH, Costa CA, Madeira LM. Experimental design to optimize the degradation of the synthetic dye Orange II using Fenton's reagent. Catal. Today 2005;107:68-76.

36. Aygun A, Yilmaz T, Nas B, Berktay A. Effect of temperature on Fenton oxidation of young landfill leachate: Kinetic assessment and sludge properties. Global Nest J. 2012;14:487-495.

37. Karatas M, Argun YA, Argun ME. Decolorization of antraquinonic dye, Reactive Blue 114 from synthetic wastewater by Fenton process: Kinetics and thermodynamics. J. Ind. Eng. Chem. 2012;18:1058-1062.

38. Lucas MS, Peres JA. Decolorization of the azo dye Reactive Black 5 by Fenton and photo-Fenton oxidation. Dyes Pigm. 2006;71:236-244.

39. Kwon BG, Lee DS, Kang N, Yoon J. Characteristics of p-chlorophenol oxidation by Fenton's reagent. Water Res. 1999;33:2110-2118.

40. Wang S. A comparative study of Fenton and Fenton-like reaction kinetics in decolourisation of wastewater. Dyes Pigm. 2008;76:714-720.

41. Tekin H, Bilkay O, Ataberk SS, et al. Use of Fenton oxidation to improve the biodegradability of a pharmaceutical wastewater. J. Hazard. Mater. 2006;136:258-265. 